\title{
The Promotional Effect of Health Education on the Medical Service Utilization of Migrants: Evidence From China
}

\author{
Yihao Tian ${ }^{1,2}$, Tao Luo ${ }^{1}$ and Yuxiao Chen ${ }^{3 *}$ \\ ${ }^{1}$ Department of Public Service Management and Public Policy, School of Public Administration, Sichuan University, \\ Chengdu, China, ${ }^{2}$ Social Development and Social Risk Control Research Center of Sichuan Philosophy and Social Sciences \\ Key Research Base, Chengdu, China, ${ }^{3}$ Department of Public Administration, School of Politics and Public Administration, \\ Zhengzhou University, Zhengzhou, China
}

\section{OPEN ACCESS}

Edited by:

Ajantha Sisira Kumara University of Sri Jayewardenepura,

Sri Lanka

Reviewed by:

Ujjaini Mukhopadhyay, Behala College, India

Tilahun Abdeta,

Haramaya University, Ethiopia

${ }^{*}$ Correspondence: Yuxiao Chen chenyuxiao1990@foxmail.com

Specialty section:

This article was submitted to

Health Economics,

a section of the journal

Frontiers in Public Health

Received: 20 November 2021 Accepted: 24 December 2021 Published: 28 January 2022

Citation:

Tian Y, Luo T and Chen Y (2022) The

Promotional Effect of Health Education on the Medical Service Utilization of Migrants: Evidence From China. Front. Public Health 9:818930. do: 10.3389/fpubh.2021.818930
There were 376 million migrants in China by 2020, who made significant contributions to urban development. However, they used limited medical services and had lower self-reported health status than inflow city residents. Based on this, this study uses the cross-sectional data of the 2017 China Migrants Dynamic Survey (CMDS) to construct a multiple linear regression model to empirically study the role of health education in improving medical services utilization for migrants. It finds that compared to migrants without health education, the probability of the medical service utilization for migrants with health education has increased significantly, and counseling is more effective than other methods for health education. This promotion effect of health education has been established after a series of robustness tests. Furthermore, this study finds that the closer the migrants are to medical service resources, the greater the effect of health education on medical services utilization for migrants. The heterogeneity test shows that the effect of health education on medical services utilization for migrants is greater among the non-elderly and those with lower education levels. From the perspective of health education, the findings in this study provide empirical evidence to support the government in formulating policies to improve the utilization of medical services for migrants and reduce health inequality.

Keywords: the migrants, health education, medical service utilization, medical service resources, age heterogeneity, education heterogeneity

\section{INTRODUCTION}

Migration is an indispensable part of the contemporary social, political, and economic worlds (1). The unprecedented economic growth and urbanization over the past few decades in China has caused a large-scale increase in the number of internal migrants (2-4). As shown in Figure 1, their numbers have reached nearly 376 million, according to China's seventh national census in 2020, and accounting for $27 \%$ of China's total population. This means that, on average, one in four households is inhabited by a migrant. However, migrants are discriminated against in many areas of life, such as education, employment, income, social integration (5-12), and particularly health services (13-16). Compared with residents with household registration (Hukou) of the inflow cities, the utilization of medical services by migrants is significantly lower. According to the $5^{\text {th }}$ China National Health 


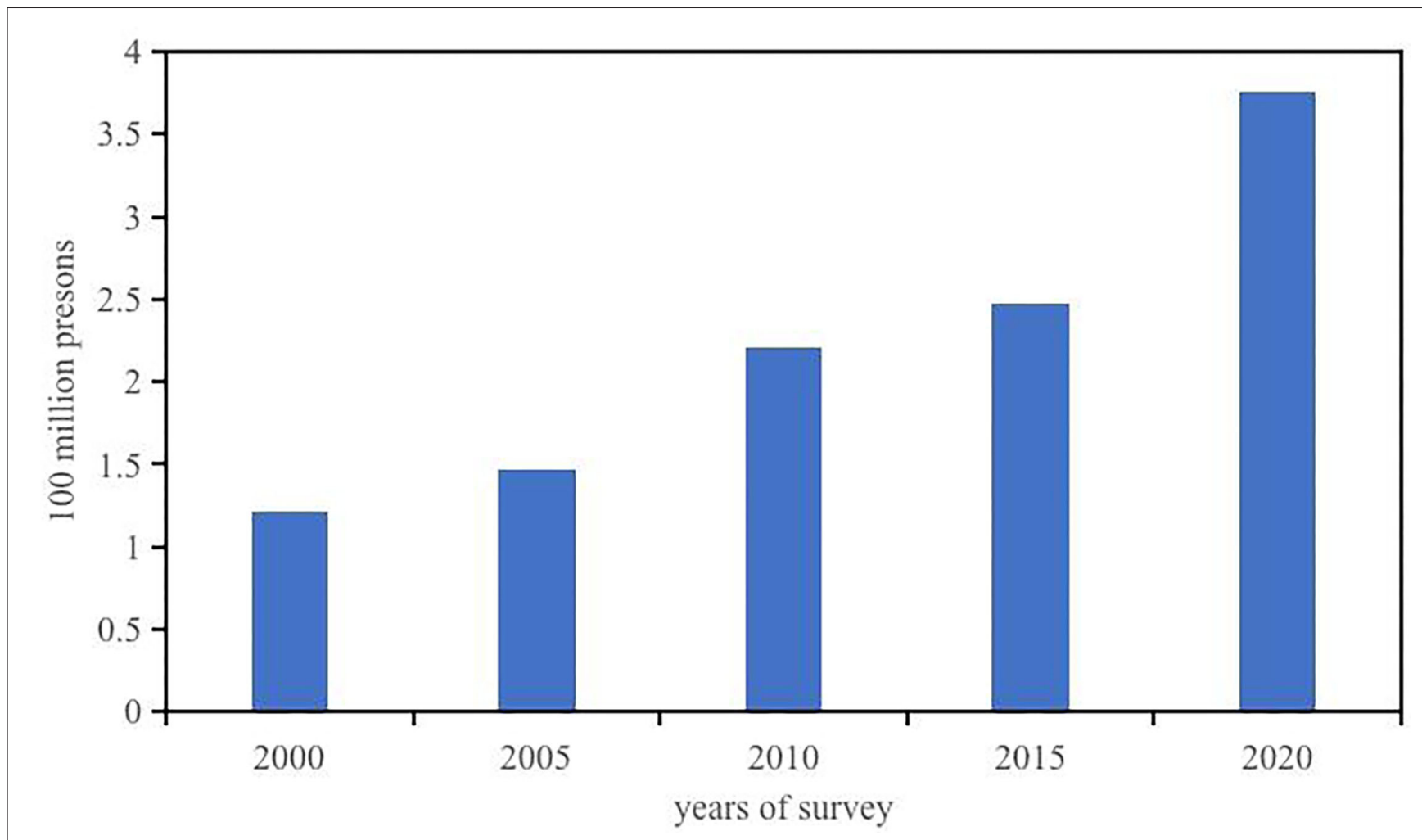

FIGURE 1 | The changing trend of migrants in China. Data sources from National Bureau of Statistics of China.

Services Survey, the hospitalization rate of the migrants due to illness (excluding childbirth) was 4.0\%, much lower than the 8.2\% of urban residents and $8.0 \%$ of rural residents $(17,18)$. These migrants have a lower level of education; $83 \%$ of them work in construction, catering, and other industries for heavy, highintensity, long-term work, which increases the risk of illness (19, 20). The risk of diseases and the lower utilization rate of medical services result in the deterioration of the health of migrants and severe health inequality. It is of great significance to explore the utilization of medical services for migrants from different angles, to improve the health of migrants and reduce health inequality.

The three causes of this low utilization of medical services have been summarized in the literature. First, there is a lack of medical insurance in inflow cities. According to the 2017 China Migrants Dynamic Survey (CMDS), only $21.91 \%$ of the migrants have medical insurance in the place of inflow. The social insurance system for migrant workers in China has poor portability and fragmentation (21). The medical insurance system in China is coordinated by counties or cities, which means different counties and cities have different medical insurance policies, such as Insurance financing and benefits. If medical services are used outside of where medical insurance is purchased, the reimbursement of medical expenses will be low or even non-reimbursable, and the process will become

Abbreviations: IV, instrumental variable; CMDS, china migrants dynamic survey. cumbersome (22). Moreover, owing to the restrictions of the household registration system (Hukou), migrant workers suffer from institutional discrimination in the job market. They have difficulty participating in local social insurance in the inflow cities (22). The social insurance for employees is paid by the firm and the employee in China, with the firm contributing about $80 \%$ of the premium. The social insurance cost of employees already accounts for more than $40 \%$ of the labor cost of Chinese firms, which is significantly higher than that in other Asian countries (23). Most firms that employ migrants are labor-intensive, and have relatively low profit margins. Social insurance costs increase the operating burden on firms. Consequently, many of these firms choose not to provide insurance to their employees (2430). Therefore, the lack of medical insurance in inflow cities leads to migrants paying a higher cost to have medical services than local residents, and thus, reducing their utilization.

Second, the demand characteristics of migrants are an important reason for their low utilization of medical services. Migrant workers, who are relatively less educated, mostly work in labor-intensive industries, such as construction and manufacturing, and earn a low income. Due to these factors, they often choose to increase their current income, and do not avail medical services when they get sick (31).

Third, health literacy among migrants is low. With a lack of knowledge about health, migrants prefer to self-heal rather than access medical services when they get sick. They tend to seek medical assistance when their condition worsens (32). 
This indicates that migrants have low health literacy, hardly pay attention to illnesses, and would not seek medical services even if they could access them.

Health education is considered an important way to improve health literacy (33). Health education refers to a planned, organized, and systematic social education activity to make people consciously adopt behaviors and lifestyles that are beneficial to health, eliminate or reduce factors risking their health, prevent diseases, improve health conditions for better life quality. The Chinese government has proposed the Action Plan for Health Education and Promotion of Migrants (20162020) to improve health literacy among migrants. The action intends to provide health education to migrants through health departments, communities, enterprises, and schools, including public health, disease prevention, reproductive health, and mental health education. The purpose of this action plan is to increase knowledge about health, enhance health awareness among migrants to improve their health literacy and utilization of medical services, further improve the health of migrants, and, at the same time, promote the implementation of health policies and the construction of a healthy environment. However, can health education be effective in increasing medical service utilization among migrants? How can health education be conducted more effectively? Does the impact of health education vary depending on the accessibility of medical services and certain characteristics of migrants? The current literature does not adequately address these questions.

Based on the above knowledge gap, using data from the CMDS, this study empirically studied the impact of health education on the medical service utilization of migrants with a multiple linear regression model and a logit model, and identified the moderating effect of the accessibility of medical services. It also verified the heterogeneous impact of health education on different age and education groups. This study enriches the understanding of the factors affecting the medical service utilization of the migrants. It is useful for formulating policies that improve the health literacy of migrants and improve migrant's health.

\section{METHODOLOGY}

\section{Data Source}

The dataset used in this study comes from the 2017 (CMDS), conducted by the National Health Commission, P.R. China. The CMDS subjects are migrant workers from 31 provinces, autonomous regions, municipalities, and the Xinjiang Production and Construction Corps. These subjects lived in inflow cities for more than 1 month and did not have local Hukou. The data has strong representativeness and a rich set of variables. The survey encompasses the basic characteristics of migrants, and their employment, family members, insurance participation, and health status. After excluding observations with missing key variables, a total of 77,837 observations were obtained.

\section{Variables}

\section{Dependent Variable}

The dependent variable in this study was the medical service utilization of migrants. In the CMDS, respondents were asked to answer the question, "In the past year, did you use medical services when you had a diarrhea/fever/rash/jaundice/ conjunctival swelling/cold?" We established six medical service utilization variables for six different diseases. The answer to "yes" was coded as "1," defining the utilization of medical service, "no" was coded as " 0 ," defining the non-utilization of medical service, and "unclear" was coded as a missing value. We conducted a benchmark regression on six medical service utilization variables separately to analyze the effect of health education on the medical service utilization of migrants for different diseases. To study the overall medical service utilization of the migrants, if the respondent had any of the above-mentioned diseases and used medical services, it will be coded as "1," demonstrating that medical service utilization occurred. Otherwise, it will be coded as "0," and the respondent without disease will be coded as a missing value.

\section{Explanatory Variable}

The core explanatory variable in this study was health education. Respondents were asked to answer separately "In the past year, did you receive health education on occupational diseases/AIDS/ reproductive health and contraception/tuberculosis/smoking/mental health/chronic diseases/maternal and child health/self-help in public emergencies?" If the respondent had participated in any health education, it will be coded as "1," defining that received health education; otherwise it will be coded as " 0 ."

\section{Control Variables}

To obtain the effects of health education on the medical service utilization of migrants, we controlled other factors that may affect it, including personal and family characteristics. Personal characteristics include gender, age, education, political identity, and industry type; family characteristics include Hukou, marital status, family size, and household income. And we also controlled medical insurance and native perception. In addition, we controlled the inflow county fixed effects.

\section{Gender}

The difference in health between men and women has been shown in multiple studies (34-36). Therefore, we controlled the dummy variable for gender in this study (female $=0$, male $=1$ ).

\section{Age}

We calculated the specific age of the respondents as of May 2017, which was the time of the survey, based on their month and year of birth, which is a continuous variable.

\section{Education}

We converted respondents' education level into years, specifically, less than elementary $=0$, elementary $=6$, middle school $=9$, senior middle school/technical secondary school $=$ 
12 , undergraduate/junior college $=15$, and postgraduate $=19$. This is a continuous variable.

\section{CPC Identity}

In China, the Communist Party of China (CPC) identity is a unique social capital with the collective value of all social networks (37). Migrants with CPC membership have more social capital and fewer barriers to accessing medical services. Therefore, we controlled for the dummy variable for CPC membership (CPC member $=1$, others $=0$ ).

\section{Industry}

We include a dummy variable for the industry in which a migrant works in the model (primary industry $=1$; secondary industry $=$ 2 ; tertiary industry $=3$ ).

\section{Hukou}

The household registration system (Hukou) has caused a split in the provision of public services, including medical services, between urban and rural areas in China. It is one of the most important reasons for emerging migrants (38-40). We controlled for the dummy variable for the type of Hukou (rural Hukou $=0$, others $=1$ ).

\section{Marital Status}

We divided the marital status of the migrants into married and unmarried. Singles, divorced, widowed, and cohabiting were considered unmarried, and first marriage or remarriage were considered married. This was measured as a dummy variable (unmarried $=0$, married $=1$ ).

\section{Family Size}

It refers to the number of migrant family members. Family members pay attention to and support each other. There is a learning and peer effect within the family, which makes it easier to contact each other, share health-related knowledge, and improve health literacy (41). This is a continuous variable.

\section{Household Income}

Income is an important determinant of health and medical service utilization (42). China has a strong family concept, and when an illness is encountered, the family shares the burden. Therefore, we controlled household income rather than individual income, which is a continuous variable.

\section{Medical Insurance}

As mentioned above, medical insurance is a key determinant for the medical service utilization of migrants (43-46). The CMDS surveyed the participation of the migrants in five categories of medical insurance. If the respondent participated in at least one kind of medical insurance, we coded it as "1," indicating participation in medical insurance; otherwise it will be coded as " 0 ." This was a dummy variable.

\section{Native Perception}

The impact of social integration on health has been increasingly emphasized (47-49). Social integration facilitates the utilization of medical services. The question "Do you agree with the statement 'I feel I am already a native'?" reflects the respondent's subjective level of social integration. The answer of "strongly disagree" was coded as " 0 ," "disagree" was coded as "1," "agree” was coded as " 2 ," and "strongly agree" was coded as " 3 ."

\section{Regional Effects}

We controlled for the regional effect at the county level, and the region was a dummy variable measured by the county where respondents inflowed. Compared to previous studies controlling at the provincial level, this increases the reliability of this study.

\section{Empirical Model}

The empirical model in this study is used to test the impact of health education on the medical service utilization of migrants, that is, whether health education for migrants will promote their medical service utilization. The basic model is as follows:

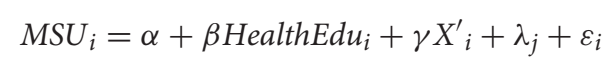

where $M S U_{i}$ is the dependent variable representing the medical service utilization of migrant $i$. $\alpha$ is a constant. HealthEdu is the explanatory variable that this study interested in, representing the health education received by migrant $i . X^{\prime}{ }_{i}$ represents a series of control variables that may affect the medical service utilization of migrant $i$, including personal characteristics, family characteristics, and other factors. $\lambda_{j}$ indicates the fixed effect of the inflow county, which controls the factors change with county and does not change over time. $\varepsilon_{i}$ is the error term. We use a two-stage least squares regression with an instrumental variable (IV) to address the problem of endogeneity, and the details are presented in Section results.

In the robustness test, as our dependent variable $M S U_{i}$ is a dummy variable, we performed a logit model for the robustness test, and the model is as follows:

$$
\ln \left(\frac{p_{i}}{1-p_{i}}\right)=\alpha+\beta \text { HealthEdu } u_{i}+\gamma X_{i}^{\prime}+\lambda_{j}+\varepsilon_{i}
$$

where, $p_{i}$ is the probability that medical service utilization occurs after the illness of migrant $i$ and $1-p_{i}$ is the probability that medical service utilization does not occur. The other variables are the same as in Equation (1).

\section{RESULTS}

\section{Descriptive Statistics}

Descriptive statistics for all variables are shown in Table 1. Regarding the dependent variable, $40.24 \%$ of migrants made use of medical services after an illness. Regarding the explanatory variable, $73.09 \%$ of migrants received health education. As shown in Table 2, we divided the sample into two subsamples based on the explanatory variable (health education). We performed descriptive statistics separately for the dependent variable (medical service utilization). It was found that, compared to the migrants who did not receive any health education, the mean medical service utilization of the migrants who received 
TABLE 1 | Descriptive statistics.

\begin{tabular}{|c|c|c|c|c|}
\hline Variable & Item & Freq. & Per & cent \\
\hline \multirow[t]{2}{*}{ Medical service utilization } & Yes $=1$ & 41,815 & 40 & .24 \\
\hline & Not $=0$ & 62,089 & & .76 \\
\hline \multirow[t]{2}{*}{ Health education } & Yes $=1$ & 112,989 & 73 & 3.09 \\
\hline & Not $=0$ & 41,597 & 26 & .91 \\
\hline \multirow[t]{2}{*}{ Gender } & Male $=1$ & 87,871 & 51 & 69 \\
\hline & Female $=0$ & 82,118 & & 31 \\
\hline \multirow[t]{2}{*}{ CPC identity } & Yes $=1$ & 8,463 & & 98 \\
\hline & Not $=0$ & 161,526 & 95 & .02 \\
\hline \multirow[t]{3}{*}{ Industry } & Primary industry $=1$ & 3,307 & & 36 \\
\hline & Secondary industry $=2$ & 50,570 & 36 & .16 \\
\hline & Tertiary industry $=3$ & 85,965 & 61 & .47 \\
\hline \multirow[t]{2}{*}{ Marital status } & Married $=1$ & 138,083 & 81 & .23 \\
\hline & Unmarried $=0$ & 31,906 & 18 & 3.77 \\
\hline \multirow[t]{2}{*}{ Hukou } & Rural $=0$ & 132,555 & & .98 \\
\hline & Others $=1$ & 37,434 & & .02 \\
\hline \multirow[t]{2}{*}{ Medical insurance } & Have $=1$ & 156,071 & & .81 \\
\hline & Not $=0$ & 13,918 & & 19 \\
\hline \multirow[t]{4}{*}{ Native perception } & Strongly disagree $=0$ & 5,304 & & 12 \\
\hline & Disagree $=1$ & 35,405 & 20 & .83 \\
\hline & Agree $=2$ & 86,635 & 50 & .97 \\
\hline & Strongly agree $=3$ & 42,645 & & .09 \\
\hline Variable & Mean & SD & Min & Max \\
\hline Age (year) & 36.99 & 11.08 & 16 & 97 \\
\hline Education (year) & 10.11 & 3.418 & 0 & 19 \\
\hline Family size & 3.140 & 1.200 & 1 & 10 \\
\hline Household income (per month) & 7.136 & 5.759 & -90 & 200 \\
\hline
\end{tabular}

The unit of household income is thousand CNY.

TABLE 2 | The gap in medical service utilization between the migrants with and without health education.

\begin{tabular}{lllllll}
\hline Variable & \multicolumn{3}{c}{ Health education } & T-test \\
\cline { 2 - 4 } Medical service utilization & \multicolumn{2}{c}{ Yes } & & No & \\
\cline { 2 - 3 } & Mean & Sd & & Mean & Sd & Diff \\
\hline & 0.419 & 0.493 & 0.345 & 0.475 & $0.074^{\star \star \star}$
\end{tabular}

${ }_{* * *}^{* *}$, and ${ }^{*}$ represent significance at the 1, 5, and 10\% levels, respectively.

health education is higher. It is statistically significant at the $1 \%$ level.

Concerning the control variables, $51.69 \%$ of the sampled migrants were male. The age of the migrants in the total sample ranges from 16 to 97 years, with a mean age of about 37 years. The average education level of the sampled migrants is 10.11 years, with a minimum of 0 years (illiteracy) and a maximum of 19 years (postgraduate). The percentage of CPC membership among migrants is only 4.98 , and $97.64 \%$ of migrants work in the secondary and tertiary industries. In terms of marital status, $81.23 \%$ of the migrants were married, and $18.77 \%$ were unmarried. On average, there are 3.14 members in each migrant family in the sample, with family sizes ranging from 1 to 10 . The average monthly household income was 7,136 CNY in 2017. The percentage of rural Hukou among migrants is even larger, reaching $77.98 \%$. We found that most Chinese migrants have medical insurance. The medical insurance coverage rate is $91.81 \%$. Finally, in terms of social integration, the mean value of native perception of the total sample was 2.98. Specifically, for the statement "I feel I am already a native," $3.12 \%$ of the migrants strongly disagreed, $20.83 \%$ disagreed, 50.97\% agreed and $25.09 \%$ strongly agreed.

\section{Benchmark Regression}

The benchmark regression results in columns (1)-(6) of Table 3, show the impact of health education on medical service utilization of migrants for different diseases, and the result in column (7) shows the overall impact. All estimates controlled county-fixed effects. The results in columns (1)-(6) show that health education has a positive in?uence on the medical service utilization of migrants, after controlling for other variables that may affect medical service utilization. The coefficients for health education are statistically significant at the $1 \%$ level for all diseases, except jaundice and conjunctival swelling. After receiving health education, the probability of medical service utilization by the migrants increased by $4.5,3.5,5.5$, and $5.5 \%$ after having diarrhea, fever, rash, and cold, respectively. As shown in column (7), from the general view of medical service utilization, the coefficient of health education is also statistically significant at the $1 \%$ level. Receiving health education led to a $5.2 \%$ average increase in the medical service utilization of the migrants after an illness, with other factors stay unchanged. The above results indicate that health education promotes the medical service utilization of migrants.

About the results of the control variables in column (7) of Table 3, the effects of the control variables are mostly in line with our expectations, and are consistent with previous studies. Compared to women, men use fewer medical services when they get sick. The effect of age on the medical service utilization of migrants is significant, but small. Compared to the primary industry, working in the secondary and tertiary industries reduces the utilization of medical services by migrants. Education, CPC identity, marital status, and family size affect medical services in the same direction as expected and did not significantly affect the medical service utilization of migrants. Rural Hukou depresses the utilization of medical services by migrants. Similarly, to a certain extent, household income improves the utilization of medical services by migrants. We find that the coefficient of medical insurance is positive and statistically significant at the $1 \%$ level, which means that migrants with medical insurance use medical services more. In addition, migrants with higher levels of social integration use more medical services.

\section{Solving the Problem of Endogeneity}

Although the model in this study controls the observable factors that affect the utilization of medical services for migrants, there may still be some unobservable variables that will affect the 
TABLE 3 | The effect of health education on medical service utilization of the migrants.

\begin{tabular}{|c|c|c|c|c|c|c|c|}
\hline Variable & $\begin{array}{c}(1) \\
\text { Diarrhea }\end{array}$ & $\begin{array}{c}\text { (2) } \\
\text { Fever }\end{array}$ & $\begin{array}{c}\text { (3) } \\
\text { Rash }\end{array}$ & $\begin{array}{c}\text { (4) } \\
\text { Jaundice }\end{array}$ & $\begin{array}{c}\text { (5) } \\
\text { Conjunctival swelling }\end{array}$ & $\begin{array}{l}(6) \\
\text { Cold }\end{array}$ & $\begin{array}{c}(7) \\
\text { Overall }\end{array}$ \\
\hline \multirow[t]{2}{*}{ Health education } & $0.045^{\star \star \star}$ & $0.035^{\star \star \star}$ & $0.055^{\star \star \star}$ & 0.075 & 0.040 & $0.055^{\star \star \star}$ & $0.052^{\star \star \star}$ \\
\hline & $(0.008)$ & $(0.010)$ & $(0.020)$ & $(0.150)$ & $(0.026)$ & $(0.004)$ & $(0.004)$ \\
\hline \multirow[t]{2}{*}{ Gender } & $-0.034^{\star \star \star}$ & $-0.025^{\star \star \star}$ & $-0.059^{\star \star \star}$ & -0.050 & $-0.066^{\star \star \star}$ & $-0.015^{\star \star \star}$ & $-0.023^{\star \star \star}$ \\
\hline & $(0.007)$ & $(0.008)$ & $(0.016)$ & (0.083) & $(0.022)$ & $(0.004)$ & $(0.004)$ \\
\hline \multirow[t]{2}{*}{ Age } & 0.000 & $-0.004^{\star \star \star}$ & $-0.004^{\star \star \star}$ & $0.008^{\star}$ & -0.001 & $-0.002^{\star \star \star}$ & $-0.002^{\star \star \star}$ \\
\hline & $(0.000)$ & $(0.001)$ & $(0.001)$ & $(0.004)$ & $(0.001)$ & $(0.000)$ & $(0.000)$ \\
\hline \multirow[t]{2}{*}{ Education } & $-0.003^{\star \star}$ & 0.002 & 0.003 & 0.013 & 0.002 & -0.001 & -0.000 \\
\hline & $(0.001)$ & $(0.002)$ & $(0.003)$ & $(0.011)$ & $(0.004)$ & $(0.001)$ & $(0.001)$ \\
\hline \multirow[t]{2}{*}{ CPC identity } & 0.013 & 0.002 & -0.010 & $0.964^{\star \star \star}$ & $-0.133^{\star \star \star}$ & -0.001 & 0.005 \\
\hline & $(0.016)$ & $(0.019)$ & $(0.035)$ & $(0.179)$ & $(0.045)$ & $(0.008)$ & $(0.008)$ \\
\hline \multirow[t]{2}{*}{ Secondary industry } & -0.010 & 0.015 & -0.046 & -0.069 & 0.001 & $-0.024^{*}$ & $-0.033^{\star \star}$ \\
\hline & $(0.026)$ & $(0.029)$ & (0.055) & (0.139) & $(0.066)$ & $(0.014)$ & $(0.014)$ \\
\hline \multirow[t]{2}{*}{ Tertiary industry } & -0.032 & -0.010 & -0.063 & -0.088 & -0.004 & $-0.051^{\star \star \star}$ & $-0.058^{\star \star \star}$ \\
\hline & $(0.026)$ & $(0.029)$ & $(0.054)$ & $(0.144)$ & $(0.065)$ & $(0.013)$ & $(0.013)$ \\
\hline \multirow[t]{2}{*}{ Marital status } & -0.003 & 0.014 & 0.028 & -0.163 & -0.021 & 0.009 & 0.005 \\
\hline & $(0.011)$ & $(0.013)$ & (0.026) & $(0.125)$ & $(0.034)$ & $(0.006)$ & $(0.006)$ \\
\hline \multirow[t]{2}{*}{ Family size } & 0.000 & 0.006 & -0.003 & 0.010 & -0.013 & 0.001 & 0.001 \\
\hline & $(0.004)$ & $(0.004)$ & $(0.008)$ & $(0.036)$ & $(0.011)$ & $(0.002)$ & $(0.002)$ \\
\hline \multirow[t]{2}{*}{ Hukou } & $0.020^{\star \star}$ & 0.010 & -0.016 & 0.128 & $0.067^{\star \star}$ & $0.024^{\star \star \star}$ & $0.019^{\star \star \star}$ \\
\hline & $(0.010)$ & $(0.012)$ & $(0.022)$ & $(0.085)$ & $(0.030)$ & $(0.005)$ & $(0.005)$ \\
\hline \multirow[t]{2}{*}{ Household income } & -0.000 & 0.001 & 0.001 & -0.008 & 0.003 & $0.001^{\star}$ & $0.001^{\star \star \star}$ \\
\hline & $(0.001)$ & $(0.001)$ & $(0.001)$ & $(0.011)$ & $(0.002)$ & $(0.000)$ & $(0.000)$ \\
\hline \multirow[t]{2}{*}{ Medical insurance } & $0.039^{\star \star \star}$ & $0.053^{\star \star \star}$ & $0.102^{\star \star \star}$ & 0.215 & 0.048 & $0.022^{\star \star \star}$ & $0.027^{\star \star \star}$ \\
\hline & $(0.013)$ & (0.016) & $(0.031)$ & $(0.161)$ & $(0.040)$ & $(0.007)$ & $(0.007)$ \\
\hline \multirow[t]{2}{*}{ Native perception } & $0.017^{\star \star \star}$ & 0.009 & $0.020^{\star}$ & 0.032 & $0.039^{\star \star \star}$ & $0.014^{\star \star \star}$ & $0.010^{\star \star \star}$ \\
\hline & $(0.004)$ & $(0.005)$ & (0.009) & $(0.043)$ & $(0.012)$ & $(0.002)$ & $(0.002)$ \\
\hline County fixed effects & Yes & Yes & Yes & Yes & Yes & Yes & Yes \\
\hline \multirow[t]{2}{*}{ Constant } & $0.243^{\star \star \star}$ & $0.506^{\star \star \star}$ & $0.553^{\star \star \star}$ & 0.122 & $0.326^{\star \star \star}$ & $0.353^{\star \star \star}$ & $0.428^{\star \star \star}$ \\
\hline & $(0.040)$ & $(0.046)$ & $(0.088)$ & $(0.322)$ & $(0.113)$ & $(0.020)$ & $(0.020)$ \\
\hline Observations & 17,560 & 14,981 & 4,699 & 121 & 2,782 & 72,911 & 77,837 \\
\hline R-squared & 0.116 & 0.156 & 0.201 & 0.716 & 0.260 & 0.098 & 0.088 \\
\hline
\end{tabular}

The numbers in parentheses are robust standard errors.

${ }^{* * *},{ }^{* *}$, and ${ }^{*}$ represent significance at the 1, 5, and $10 \%$ levels, respectively. The following are the same.

utilization of medical services for migrants and are related to whether the migrants receive health education. These missing variables lead to biased estimates in this study. This study uses an instrumental variable (IV) model to solve this endogenous problems and strengthen the reliability of the results. Based on the literature (50), this study applies the average number of fixed health education bulletin boards in communities within a county as the IV. Based on the question "Number of fixed health education bulletin boards in the community" in the CMDS community questionnaire, we set the variable of the average number of fixed health education bulletin boards. Theoretically, the average number of fixed health education bulletin boards in communities within a county is a qualified IV that satisfies the requirements of relevance and exclusion. The average number of fixed health education bulletin boards in communities within a county reflects how the communities in the county, where the migrants live, value health education and the popularization of health knowledge, which affects the health education they receive. This indicates that the IV we choose is closely correlated with the explanatory variable. Further, the average number of fixed health education bulletin boards in communities within a county, does not directly associate with the medical service utilization of migrants. Therefore, it qualifies the requirement of exclusion. However, since the 2017 CMDS community data were not open access, we used the 2018 data instead, and the tests illustrate that the IV is still qualified.

The result of the IV are presented in Table 4. After regression with IV, we performed a series of tests. The unidentifiability test showed that the Kleibergen-Paap rk LM was 198.294, rejecting the original hypothesis of unidentifiability. The weak identification test showed that the Kleibergen-Paap rk Wald Fvalue was 201.484, much greater than the empirical criterion 10 and greater than all thresholds, confirming that the average number of fixed health education bulletin boards in communities 
TABLE 4 | The effect of health education on medical service utilization of the migrants (IV model).

\begin{tabular}{lc}
\hline Variable & Medical service utilization \\
\hline Health education & $0.580^{\star * *}$ \\
& $(0.093)$ \\
Control variables & Controlled \\
County fixed effects & No \\
Observations & 69,079
\end{tabular}

The control variables are consistent with model 1 and because of space limitations, there is no report here.

${ }_{* * *}^{* * *}$, and ${ }^{*}$ represent significance at the 1, 5, and 10\% levels, respectively.

TABLE 5 | The effect of health education on medical service utilization of the migrants (Logit model).

\begin{tabular}{lc}
\hline Variable & Medical service utilization \\
\hline Health education & $1.271^{\star * \star}$ \\
& $(0.025)$ \\
Control variables & Controlled \\
County fixed effects & Yes \\
Observations & 77504 \\
Log-likelihood & -48747.418 \\
Chi2 & 5629.338 \\
\hline
\end{tabular}

The coefficient is presented as odds ratio. The control variables are consistent with model 1 and due to space limitations, there is no report here.

${ }^{* * *},{ }^{* *}$, and ${ }^{*}$ represent significance at the 1, 5, and 10\% levels, respectively.

within a county is a strong IV for health education. These results indicate that the proposed IV is reliable. The result of IV regression is also statistically significant at the $1 \%$ level, leading to the conclusion that health education for migrants effectively promotes their utilization of medical services after an illness, a finding consistent with the basic regression.

\section{Robustness Test}

To further enhance our confidence in the research findings, we perform robustness tests by using the logit model and the alternating dependent variable.

\section{Logit Model}

As the dependent variable of this study, medical service utilization is binary. We further examine the effect of health education on medical service utilization of the mobile population using a logit model. Table 5 shows the result of the logit regression presented as odds ratio. It can be found that controlling for other conditions, the probability of using medical services after an illness significantly increased for the migrants who received health education than those who did not. This is consistent with the findings of the benchmark regression.

\section{Alternate Dependent Variable}

Further, to increase the robustness of the findings, we replaced the dependent variable in this study. Based on the question "Where did you go first for medical services the last time
TABLE 6 | The effect of health education on medical service utilization of the migrants (Alternate dependent variable).

\begin{tabular}{lccc}
\hline Variable & $\begin{array}{c}(\mathbf{1}) \\
\text { Benchmark }\end{array}$ & $\begin{array}{c}\text { (2) } \\
\text { IV }\end{array}$ & $\begin{array}{c}\text { (3) } \\
\text { Logit model }\end{array}$ \\
\hline Health education & $0.025^{\star \star *}$ & $0.702^{\star \star *}$ & $1.193^{\star * \star}$ \\
& $(0.004)$ & $(0.085)$ & $(0.032)$ \\
Control variables & Controlled & Controlled & Controlled \\
County fixed effects & Yes & No & Yes \\
Constant & $0.773^{\star \star *}$ & $0.435^{\star \star *}$ & 0.690 \\
& $(0.017)$ & $(0.046)$ & $(0.473)$ \\
Observations & 62,197 & 56,357 & 58,564 \\
R-squared & 0.089 & - & - \\
Log-likelihood & - & - & -25814.399 \\
Chi2 & - & - & 3731.745 \\
\hline
\end{tabular}

The control variables are consistent with model 1 and because of space limitations, there is no report here. The coefficient of logit model in column and is presented as odds ratio. ${ }^{* \star *},{ }^{* *}$, and ${ }^{*}$ represent significance at the 1, 5, and 10\% levels, respectively.

you were sick, injured, or unwell?" in the questionnaire, we constructed a new dependent variable to measure the medical service utilization of migrants. If the respondent was treated at a local community health service station, individual clinic, general/specialized hospital, pharmacy, hometown or another place, the respondent was coded as " 1 ," defining that medical service utilization occurred. If the respondent answered "No treatment" the respondent was coded as "0," representing that no medical service utilization occurred. The benchmark, IV, and logit regression results after replacing the dependent variable are shown in columns (1)-(3) of Table 6, respectively.

It can be observed from column (1) of Table 6 that after controlling for other variables of the migrants and county-fixed effects, the coefficient of health education is positive and still statistically significant at the $1 \%$ level. We also estimated with an IV, which is the average number of fixed health education bulletin boards in communities within a county. As column (2) of Table 6 shows, the coefficient of health education remained positive and statistically significant at the $1 \%$ level. Finally, logit regression analysis was performed. The odds ratio for health education in column (3) of Table 6 is similar to Table 5, and remains statistically significant at the $1 \%$ level. Overall, according to the results of the robustness tests reported in Tables 5, 6, health education for migrants enhances their utilization of medical services after an illness. Therefore, the regression results reported in Table 3 are robust.

\section{Further Exploration on the Methods of Health Education}

We attempted to explore the different impacts of educational methods on the medical service utilization of migrants. The migrants in China received health education through health lectures, promotion materials (paper or video), bulletin boards and electronic displays, community SMS/WeChat/website, public health consultation, and individual consultation. We classified public health and individual counseling as counseling, 
TABLE 7 | The effect of different health education methods on medical service utilization of the migrants.

\begin{tabular}{|c|c|c|}
\hline Variable & $\begin{array}{c}\text { (1) } \\
\text { Non-counseling }\end{array}$ & $\begin{array}{c}\text { (2) } \\
\text { Counseling }\end{array}$ \\
\hline Health education & $\begin{array}{l}0.028^{\star \star \star} \\
(0.005)\end{array}$ & $\begin{array}{l}0.079^{\star * \star} \\
(0.005)\end{array}$ \\
\hline Control variables & Controlled & Controlled \\
\hline County fixed effects & Yes & Yes \\
\hline Constant & $\begin{array}{l}0.436^{\star \star \star} \\
(0.025)\end{array}$ & $\begin{array}{l}0.426^{\star \star \star} \\
(0.025)\end{array}$ \\
\hline Observations & 48,438 & 48,880 \\
\hline R-squared & 0.094 & 0.104 \\
\hline
\end{tabular}

and other methods of health education as non-counseling. Table 7 presents the results. The coefficients for both types of health education methods were positive and significant at the $1 \%$ level, indicating that either method of health education can improve the medical service utilization of the migrants. However, the promotion effect of counseling is more greater. In summary, compared to other health education methods, counseling is more effective in improving the medical service utilization of migrants.

\section{Moderating Effect Analysis}

Based on the results of the benchmark regression and the robustness test, we are confident that health education has a positive effect on the medical service utilization of migrants. To explore whether other factors influence the effect of health education on medical service utilization, we conducted a moderating effect analysis.

Based on the literature, many barriers prevent migrants from medical services $(51,52)$, and distance and transportation are important factors $(53,54)$. Thus, we hypothesized that the effect of health education on the medical service utilization of migrants is moderated by the accessibility of medical services. Based on the question "How long does it take to go from your residence to the nearest medical service institution?" in the questionnaire, we constructed a variable for the accessibility of medical services as a moderator variable. There are four options for this question: "within 15 min," "15-30 min," "30-60 min," and "more than 1 h." We coded "within 15 min" as "1," defining the accessibility of medical services, and the other options as " 0 ." We added the interaction term of the explanatory variable (health education), and moderator variable (the accessibility of medical services), to the regression model. The result of the moderating effect analysis are presented in Table 8. It can be found that controlling for other variables and county fixed effects, the coefficient of the interaction term of health education and the accessibility of medical services is positive and statistically significant at the $1 \%$ level. This demonstrates that the accessibility of medical services positively moderates the effect of health education on medical
TABLE 8 | Moderating effect of accessibility in the effect of health education on medical service utilization of the migrants.

\begin{tabular}{lc}
\hline Variable & Medical service utilization \\
\hline Health education & $0.036^{\star \star \star}$ \\
& $(0.007)$ \\
Health education ${ }^{\star A c c e s s i b i l i t y ~}$ & $0.019^{\star \star \star}$ \\
& $(0.006)$ \\
Control variables & Controlled \\
County fixed effects & Yes \\
Observations & 77,837 \\
R-squared & 0.088
\end{tabular}

The control variables are consistent with model 1 and because of space limitations, there is no report here.

${ }^{* * *},{ }^{* *}$, and ${ }^{*}$ represent significance at the 1,5 , and $10 \%$ levels, respectively.

TABLE 9 | The effect of health education on medical service utilization of the migrants on different groups.

\begin{tabular}{|c|c|c|c|c|}
\hline \multirow[t]{3}{*}{ Variable } & \multirow{2}{*}{\multicolumn{2}{|c|}{$\begin{array}{l}\text { (1) } \\
\text { Age }\end{array}$}} & \multirow{2}{*}{\multicolumn{2}{|c|}{$\begin{array}{c}\text { (2) } \\
\text { Education }\end{array}$}} \\
\hline & & & & \\
\hline & Non-elderly & Elderly & Non-higher & Higher \\
\hline \multirow[t]{2}{*}{ Health education } & $0.053^{\star \star \star}$ & 0.044 & $0.055^{\star \star \star}$ & $0.039^{\star \star \star}$ \\
\hline & $(0.004)$ & $(0.041)$ & $(0.005)$ & $(0.010)$ \\
\hline Control variables & Controlled & Controlled & Controlled & Controlled \\
\hline County fixed effects & Yes & Yes & Yes & Yes \\
\hline \multirow[t]{2}{*}{ Constant } & $0.339^{\star \star \star}$ & $0.392^{\star \star \star}$ & $0.404^{\star \star \star}$ & $0.536^{\star \star \star}$ \\
\hline & $(0.018)$ & $(0.144)$ & $(0.020)$ & $(0.052)$ \\
\hline Observations & 76,621 & 935 & 62,472 & 15,205 \\
\hline R-squared & 0.086 & 0.423 & 0.099 & 0.112 \\
\hline Empirical $P$-value & $0.010^{\star *}$ & $0.002^{\star \star \star}$ & & \\
\hline
\end{tabular}

The control variables are consistent with model 1 and because of space limitations, there is no report here. The "Empirical P-value" is used to test the significance of the difference in the coefficients of health education between groups, obtained by self-sampling 500 times through bootstrapping.

${ }^{* * *}$, "** and * represent significance at the 1, 5, and 10\% levels, respectively.

service utilization for migrants. That is to say, health education can improve the utilization of medical services of migrants, and the closer the migrants are to medical service institutions, the stronger the effect of health education on migrants' medical services utilization.

\section{Heterogeneous Impact Analysis}

We further explore the heterogeneous impact of health education on the medical service utilization of migrants in different groups. We divided the total sample into subsamples according to age and education level, and used the basic analysis model. The results are listed in Table 9.

Referring to studies on aging, we classify the migrants who are over 60 years old as elderly and code them as " 1 ," and the migrants who are $<60$ years old are coded as " 0 " $(55,56)$. The result in column (1) of Table 9 indicate that the effect of health education on the medical service utilization of migrants is heterogeneous in 
different age groups. The effect of health education on medical service utilization among elderly migrants is not significant, and the effect is greater and significant at the $1 \%$ level for nonelderly migrants. The heterogeneous effect between age groups was significant at the $5 \%$ level through Fisher's permutation test. This indicates that health education has a stronger impact on the medical service utilization of non-elderly migrants.

Further, we explored the impact of health education on migrants with different levels of education. We coded "undergraduate/junior college" and above as "1," indicating higher education (57), and others as " 0 ." The result in column (2) of Table 9 similarly indicate that there is a heterogeneous effect in education level groups. Specifically, the effect of health education on medical service utilization for both migrants with and without higher education is significant at the $1 \%$ level, but greater for migrants who did not receive higher education. Fisher's permutation test also demonstrates that the differences here are not coincidental, and health education is more effective in promoting medical service utilization of migrants without higher education. Compared with migrants who have received higher education, those with a low level of education have relatively poorer health literacy, and thus, health education will have a greater effect.

\section{DISCUSSION}

\section{Main Findings}

Improving medical service utilization among the migrants can improve the health of the migrants and reduce health inequalities. The low utilization of health services among the migrants compared to residents is not only caused by the fragmentation of the social insurance system, but also related to the migrants' lack of health literacy. The Chinese government has taken steps to provide health education to migrants. This study examined whether health education effectively improves the health literacy of migrants, and thereby their medical service utilization.

In this study, based on a large sample of data from CMDS, we used multiple linear regression, logit regression, and instrumental variable methods to examine the effect of health education on medical service utilization among migrants and the different effects of different health education methods. We further tested the moderating effect of the accessibility of medical services and the heterogeneous effects of health education on the medical service utilization of migrants belonging to different age and education groups. We provide empirical evidence for further improving medical service utilization and conducting more effective health education among migrants.

We find that migrants significantly use more medical services after receiving health education, and this result is significant while controlling migrants' household income and medical insurance. In general, low income and the fragmentation of the social insurance system are the main reasons for the low utilization of medical services by migrants $(58,59)$. However, what is not considered is the low health literacy of the migratory population. Most migrants come from under-developed rural areas, have a heavy burden of life, poor hygiene, low health literacy, and limited knowledge about diseases. Thus, health problems do not attract their attention, and they often do not take any measures when they fall ill. After receiving health education, firstly, migrants gain knowledge about diseases and health, learn about the harm of diseases, and value their health more. Secondly, by receiving health education locally, migrants can obtain information about local access to medical services, which makes them more familiar with how to use medical services in the inflow city easily and quickly and reduces the cost of accessing medical services. As a result, the medical services utilization of migrants will be improved.

Our findings further elucidate how to conduct health education more efficiently. In practice, migrants receive many forms of health education, divided into counseling and noncounseling types. Compared to non-counseling, counseling health education is more effective in promoting medical service utilization among migrants. Through public health and personal counseling, migrants have access to one-to-one health advice, which is more efficient in health knowledge transfer. In addition, migrants can get consultations regarding their health problems and hygiene, to obtain the most compatible medical diagnosis and health care advice, and better matched health knowledge, which is more effective in improving their health literacy.

We also find that the accessibility of health care services moderates the effect of health education on medical service utilization among migrants. The closer the migrants are to medical service institutions, the stronger the effect of health education on their medical service utilization. After receiving health education, migrants make more use of medical services when they are ill. However, if migrants do not have easy access to medical services-for example, if they are too far away from a healthcare facility-it makes it more difficult for them to access medical services and further discourage them from seeking medical services, which will eventually weaken the effect of health education on migrants' medical service utilization. Conversely, if they have easy access to medical services, they will be more motivated to use medical services when they are sick.

From the age perspective, health education has a stronger effect on promoting medical service utilization among nonelderly migrants than elderly migrants. Possible reasons for this are that elderly migrants are more concerned about health issues as their physical health declines with age, and the same diseases cause more financial and health losses. On the other hand, in China, non-elderly migrants are the mainstay of their family, and bear more familial and economic responsibilities, which forces them to focus more on increasing their income rather than their health. Therefore, health education is more effective in increasing the non-elderly mobile population's attention to their health and improving their medical service utilization.

From the perspective of education, health education has a stronger effect on promoting medical service utilization among migrants with lower education levels. This is because, compared to migrants who are not well educated, migrants with undergraduate/junior college degrees and above, generally have higher health literacy (60) and pay more attention to their health problems. Hence, the effect of health education on them 
is limited. However, most migrants are not highly educated, have relatively poor health knowledge, and lack health awareness. Therefore, health education can better improve health literacy for migrants who not well educated, and increase their attention to health issues and medical service utilization.

\section{Policy Implications}

Based on the findings of our study, we offer some suggestions for reference. Migrants, communities, and the government should be aware of the importance of health education in improving medical service utilization. For migrants, they should primarily pay attention to their health problems, for their good health is their important human capital (61), and it affects their social capital $(62,63)$. Second, migrants should recognize that their health literacy is relatively low, so they should participate more actively in health education to accumulate more healthrelated knowledge, improve their health literacy, and actively use medical services for treatment when they are ill. Communities should fulfill their responsibilities of primary-level governance and focus on the health of migrants. They should work together with medical service providers to organize health education for migrants, especially public health counseling and individual counseling, which are more effective in improving the utilization of medical services.

For the government, to improve medical service utilization and reduce health inequalities among migrants, efforts should be made to develop supporting policies to promote the health of migrants, improve the accessibility of medical services, strengthen the propaganda of relevant policies and health education, and conduct health education precisely. First, promote the formation of a policy environment conducive to the medical service utilization of migrants. Health department and other departments should coordinate to form policies that facilitate the migrants' access to medical services, include them in the scope of community health services, and consider them when formulating and revising policies on health education, disease prevention, treatment, and medicine. Second, improve the accessibility of medical services for migrants. The government needs to optimize the allocation of medical service resources, innovate the service model, improve the accessibility of medical services, and ensure that the migrants have convenient access to medical services, in response to the characteristics of the local migrants' work and residence, the major health problems and health needs they face. Third, strengthen the promotion of health education and medical service policies. The government can use appropriate media forms and seek help from labor unions, associations, and non-governmental organizations, to make migrants more familiar with information regarding health education and medical service policies, as well as the contents and processes of medical services. Finally, health education could be more precise and effective. The government should keep improving the health education service model, actively carry out health education for migrants of different ages, genders, and occupations, and especially pay attention to the nonelderly and less educated migrants. It should also develop more consulting-type health education, to continuously improve efficiency regarding the enhancement of the health literacy of migrants.

\section{Strengths and Limitations}

In this study, we evaluate the effect of health education on the medical service utilization of migrants, and offer three main contributions. First, this study uses a large sample of data to empirically examine the effect of health education on improving medical service utilization among migrants. This is an important addition to the current literature on enhancing medical service utilization among migrants. Second, we studied the effect of different health education methods on improving medical service utilization among migrants, which has important practical implications for governments on how to provide better health education, and reduce health inequities. Third, this study also explores the moderating effect of the accessibility of medical services, and the heterogeneous effects of health education on medical service utilization by migrants belonging to different age and education groups; this helps in gaining a comprehensive understanding of the role of health education in enhancing medical service utilization among migrants. It also allows governments to develop better policies to alleviate health inequalities among mobile populations.

However, this study has some limitations. First, this study only investigates the effect of health education on the medical service utilization of migrants. It does not explore other important factors, such as the fragmentation of the insurance system and how to integrate. Second, due to the limitation of data, this study uses 2017 cross-sectional data. Subsequent studies with panel data would make the causal inference more robust and reliable.

\section{CONCLUSION}

Migrants have made significant contributions to China's economic and social development, yet suffer from health inequities, particularly the low utilization of medical services. This study shows that health education could improve the medical service utilization of migrants, and the effect is stronger if a counseling-type health education is conducted, or if migrants have better access to health services. The increase in medical service utilization was more prominent among non-elderly and low-education migrants after health education. In future, we will continue to explore the causes affecting medical service utilization among migrants from different demographics, to provide support for reducing health inequalities. In addition, tracking panel data could better answer the above questions and make the conclusions of causal inference more reliable.

\section{DATA AVAILABILITY STATEMENT}

Publicly available datasets were analyzed in this study. This data can be found here: China Migrants Dynamic Survey https:// chinaldrk.org.cn/wjw/\#/home. 


\section{AUTHOR CONTRIBUTIONS}

YT led and designed the study, led the data collection, analysis, and interpretation. TL contributed to the study design, provided input into the data analysis, and wrote the first draft of the manuscript. YC contributed to the study design, data interpretation, reviewed the manuscript, and helped the writing of the final draft manuscript. All the authors read and approved the final manuscript.

\section{FUNDING}

This paper was funded by Full-time postdoctoral research and development fund project of Sichuan University, Research on the Accurate Configuration of Medical Public Services

\section{REFERENCES}

1. Kurvet-Käosaar L, Ojamaa T, Sakova A. Situating narratives of migration and diaspora: an introduction. Trames J Human Soc Sci. (2019) 23:125. doi: 10.3176/tr.2019.2.01

2. Wang $\mathrm{C}$, Jing $\mathrm{C}$, Contribution to economic growth from rural-urban migrant workers and the income share in the process of urbanization. evidence from 1995-2009 in China. Actual Probl Econ. (2012) (135):245-54.

3. Hu X, Cook S, Salazar MA. Internal migration and health in China. Lancet. (2008) 372:1717-9. doi: 10.1016/S0140-6736(08)61360-4

4. Liang Z. The age of migration in China. Popul Dev Rev. (2001) 27:499524. doi: 10.1111/j.1728-4457.2001.00499.x

5. Barham B, Boucher S. Migration, remittances, and inequality: estimating the net effects of migration on income distribution. J Dev Econ. (1998) 55:307-31. doi: 10.1016/S0304-3878(98)90038-4

6. Lu Y, Wang F. From general discrimination to segmented inequality: migration and inequality in urban China. Soc Sci Res. (2013) 42:144356. doi: 10.1016/j.ssresearch.2013.06.006

7. Vakulabharanam V, Motiram S. Mobility and inequality in neoliberal India. Contemp South Asia. (2016) 24:257-70. doi: 10.1080/09584935.2016.1203862

8. Howell A. Impacts of migration and remittances on ethnic income inequality in rural China. World Dev. (2017) 94:20011. doi: 10.1016/j.worlddev.2017.01.005

9. An F, Broadbent K, Yuan F. Employment inequality among women migrant workers in China: comparative analysis from the 2014 Guangdong migrant workers survey. Asia Pac J Human Resour. (2018) 56:51838. doi: 10.1111/1744-7941.12180

10. Wu Y, Li X. Rural-urban migrants' remittances and wage inequality: evidence from China. Agric Econ. (2020) 66:12939. doi: 10.17221/53/2019-AGRICECON

11. Holt HK, Zhang X, Hu S-Y, Zhao F-H, Smith JS, Qiao Y-L. Inequalities in cervical cancer screening uptake between Chinese migrant women and local women: a cross-sectional study. Cancer Control. (2021) 28:1073274820985792. doi: 10.1177/1073274820985792

12. Ortlieb R, Winterheller J. Behind migrant and non-migrant worktime inequality in europe: institutional and cultural factors explaining differences. Br J Ind Relat. (2020) 58:785-815. doi: 10.1111/bjir.12521

13. Egger M, Minder CE, Smith GD. Health inequalities and migrant workers in switzerland. Lancet. (1990) 336:816. doi: 10.1016/0140-6736(90)93284-V

14. Amrith M, Amrith S. Migration, health and inequality in Asia. Dev Change. (2016) 47:840-60. doi: 10.1111/dech.12242

15. Carrasco-Sanz A, Leiva-Gea I, Martin-Alvarez L, del Torso S, van Esso D, Hadjipanayis A, et al. Migrant children's health problems, care needs, and inequalities: European primary care paediatricians' perspective. Child Care Health Dev. (2018) 44:183-7. doi: 10.1111/cch.12538

16. Kaur-Gill S. The COVID-19 pandemic and outbreak inequality: mainstream reporting of singapore's migrant workers in the
Empowered by Smart Technology in the Post-epidemic Era (skbsh2020-05), Independent project of School of Public Administration of Sichuan University, Research on the Accurate Supply of Medical Public Services Empowered by Big Data in the Post-epidemic Era (2020Ziyan-gongguan05), the 2020 Project of the Social Development and Social Risk Control Research Center of Sichuan Philosophy and Social Sciences Key Research Base, Research on Accurate Community Emergency Management Under the Background of Big Data (SR20A09) and the 2021 Project of the Central Universities Basic Research Funds for School of Public Administration of Sichuan University, the Development History and Future Prospects of Ethnic Higher Education under the Leadership of the Communist Party of China (2021DSDJ007). margins. Front Commun. (2020) 5:e00065. doi: 10.3389/fcomm.2020. 00065

17. Norredam M, Nielsen SS, Krasnik A. Migrants' utilization of somatic healthcare services in Europe-a systematic review. Eur J Public Health. (2010) 20:555-63. doi: 10.1093/eurpub/ckp195

18. Cai $\mathrm{M}, \mathrm{Xu} \mathrm{L}$. The utilization of hospitalization services for the migrants and the influencing factors. Chin J Hospital Stat. (2019) 26:150-3. doi: 10.3969/j.issn.1006-5253.2019.02.020

19. Sonmez S, Apostolopoulos Y, Lemke MK, Hsieh Y-C. Understanding the effects of COVID-19 on the health and safety of immigrant hospitality workers in the United States. Tour Manag Perspect. (2020) 35. doi: 10.1016/j.tmp.2020.100717. Available online at: https://www. sciencedirect.com/science/article/pii/S2211973620300842

20. Luxford CJ, Bretz SL. Moving beyond definitions: what student-generated models reveal about their understanding of covalent bonding and ionic bonding. Chem Edu Res Practs. (2013) 14:214-22. doi: 10.1039/C3RP 20154F

21. Zheng B. Development and challenges of social insurance for china's migrant population in the 30 years of reform and opening up. Chin Population Sci. (2008) 5:2-17.

22. Tian Y, Chen Y, Zhou M, Zhao S. Institutional design and incentives for migrant workers to participate in social insurance in China: evidence from a policy experiment in chengdu city. Front public health. (2021) 9:736340. doi: 10.3389/fpubh.2021.736340

23. Nielsen I, Smyth R. Who bears the burden of employer compliance with social security contributions? evidence from Chinese firm level data. Chin Econ Rev. (2008) 19:230-44. doi: 10.1016/j.chieco.2007.06.002

24. Cottani J, Demarco G. The Shift to a Funded Social Security System: The Case of Argentina. Privatizing social security. Chicago: University of Chicago Press (2008). p. 177-212.

25. Bailey C, Turner J. Strategies to reduce contribution evasion in social security financing. World Dev. (2001) 29:38593. doi: 10.1016/S0305-750X(00)00100-5

26. Nyland C, Smyth R, Zhu CJ. What determines the extent to which employers will comply with their social security obligations? evidence from Chinese firm-level data. Soc Policy Adm. (2006) 40:196-214. doi: 10.1111/j.1467-9515.2006.00484.x

27. Feng J. Incentives for participation and social insurance of Chinese urban employees. Econ Res. (2013) 48:104-17.

28. Zhao $\mathrm{Y}, \mathrm{Xu}$ J. Incentive mechanism in the reform of China's urban endowment insurance system. Economics. (2001) 1:193-206.

29. Zhao J, Mao J, Zhang L. Social insurance contribution rate, participation probability and contribution level-an empirical study of employees' and firms' evasion behavior. Economics. (2016) 15:341-72.

30. Feng J, Zhang S. The impact of social insurance contribution rates on enterprises' participation in insurance: a study based on shanghai social security policy. Shanghai Econ Res. (2012) 24:47-55. 
31. Fu Y, Lin W, Yang Y, Du R, Gao D. Analysis of diverse factors influencing the health status as well as medical and health service utilization in the floating elderly of China. BMC Health Serv Res. (2021) 21:438. doi: 10.1186/s12913-021-06410-7

32. Su S, Zhang F, Liu Q, Wang Y, Wen J, Tang X, et al. Factors associated with utilization of reproductive healthcare services among migrant women workers in Chong Qing, China. Int J Gynecol Obstet. (2014) 127:668. doi: 10.1016/j.ijgo.2014.04.005

33. Berkman ND, Sheridan SL, Donahue KE, Halpern DJ, Crotty K. Low health literacy and health outcomes: an updated systematic review. Ann Intern Med. (2011) 155:97-107. doi: 10.7326/0003-4819-155-2-201107190-00005

34. Springer KW, Stellman JM, Jordan-Young RM. Beyond a catalogue of differences: a theoretical frame and good practice guidelines for researching sex/gender in human health. Soc Sci Med. (2012) 74:181724. doi: 10.1016/j.socscimed.2011.05.033

35. Salk RH, Hyde JS, Abramson LY. Gender differences in depression in representative national samples: meta-analyses of diagnoses and symptoms. Psychol Bull. (2017) 143:783-822. doi: 10.1037/bul0000102

36. Korkmaz S, Park DJ. Comparison of safety perception between foreign and local workers in the construction industry in Republic of Korea. Saf Health Work. (2018) 9:53-8. doi: 10.1016/j.shaw.2017.07.002

37. Wang Q, Li Z, Feng X. Does the happiness of contemporary women in China depend on their husbands' achievements? J Fam Econ Issues. (2019) 40:710-28. doi: 10.1007/s10834-019-09638-y

38. Song J, Li S. Hukou's impact on labor occupation segmentation. Chin Agric Econ Rev. (2014) 6:506-22. doi: 10.1108/CAER-05-2013-0081

39. Chan KW, Liu T, Yang Y. Hukou and non-hukou migrations in China: comparisons and contrasts. Int J Popul Geogr. (1999) 5:42548. doi: 10.1002/(SICI)1099-1220(199911/12)5:6<425::AID-IJPG158>3.0. $\mathrm{CO} ; 2-8$

40. Chen C, Fan CC. China's hukou puzzle: why don't rural migrants want Urban Hukou? China Rev. (2016) 16:9-39.

41. Zhao X, Yang S. Health literacy and its improving mechanism for floating population:a research based on dynamic monitoring data in jiangsu province. Northwestern Population. (2019) 40:38-47.

42. Taresh AA, Sari DW, Purwono R. Analysis of the relationship between income inequality and social variables. evidence from indonesia. Econ Sociol. (2021) 14:103-19. doi: 10.14254/2071-789X.2021/14-1/7

43. Han J, Meng Y. Institutional differences and geographical disparity: the impact of medical insurance on the equity of health services utilization by the floating elderly population - evidence from China. Int J Equity Health. (2019) 18:91. doi: 10.1186/s12939-019-0998-y

44. Zhang F, Shi X, Zhou Y. The impact of health insurance on healthcare utilization by migrant workers in china. Int J Environ Res Public Health. (2020) 17:1852. doi: 10.3390/ijerph17061852

45. Fan X, Su M, Si Y, Zhao Y, Zhou Z. The benefits of an integrated social medical insurance for health services utilization in rural China: evidence from the China health and retirement longitudinal study. Int J Equity Health. (2021) 20:126. doi: 10.1186/s12939-02101457-8

46. Kumara AS, Samaratunge R. Health insurance ownership and its impact on healthcare utilization evidence from an emerging market economy with a free healthcare policy. Int J Soc Econ. (2020) 47:244-67. doi: 10.1108/IJSE-05-2019-0333

47. Xi S, Song Y, Li X, Li M, Lu Z, Yang Y, et al. Local-migrant gaps in healthcare utilization between older migrants and local residents in China. J Am Geriatr Soc. (2020) 68:1560-7. doi: 10.1111/jgs.16421

48. Chen Y, Zhang Y. The inequality effect of urbanization and social integration. Soc Sci China. (2016) 37:117-35. doi: 10.1080/02529203.2016.12 41497

49. Qin L, Chen C-P, Wang W, Chen H. How migrants get integrated in urban China-the impact of health insurance. Soc Sci Med. (2021) 272:113700. doi: 10.1016/j.socscimed.2021.113700
50. Zhao Y, Wang X. Does accepting public health education improve the health status of floating population: an empirical analysis based on the data of the China migrants dynamic survey in 2018. (2020) 21:61-7. doi: 10.13331/j.cnki.jhau(ss).2020.05.008

51. Rechel B, Mladovsky P, Ingleby D, Mackenbach JP, McKee M. Migration and health in an increasingly diverse Europe. Lancet. (2013) 381:123545. doi: 10.1016/S0140-6736(12)62086-8

52. Wang F. Measurement, optimization, and impact of health care accessibility: a methodological review. Ann Assoc Am Geogr. (2012) 102:1104-12. doi: 10.1080/00045608.2012.657146

53. Syed ST, Gerber BS, Sharp LK. Traveling towards disease: transportation barriers to health care access. I Community Health. (2013) 38:97693. doi: 10.1007/s10900-013-9681-1

54. McGrail MR. Spatial accessibility of primary health care utilising the two step floating catchment area method: an assessment of recent improvements. Int J Health Geogr. (2012) 11:50. doi: 10.1186/1476-072X-11-50

55. Bloom DE, Chatterji S, Kowal P, Lloyd-Sherlock P, McKee M, Rechel B, et al. Macroeconomic implications of population ageing and selected policy responses. Lancet. (2015) 385:649-57. doi: 10.1016/S0140-6736(14)61464-1

56. Harper S. Economic and social implications of aging societies. Science. (2014) 346:587-91. doi: 10.1126/science. 1254405

57. Choy LHT, Li VJ. The role of higher education in China's inclusive urbanization. Cities. (2017) 60:504-10. doi: 10.1016/j.cities.2016.04.008

58. Shaaban AN, Morais S, Peleteiro B. Healthcare services utilization among migrants in portugal: results from the national health survey 2014. J Immigr Minor Health. (2019) 21:219-29. doi: 10.1007/s10903-018-0744-3

59. Cai X, Yang F, Bian Y. Gap analysis on hospitalized health service utilization in floating population covered by different medical insurances -- case study from Jiangsu Province, China. Int J Equity Health. (2019) 18:84. doi: 10.1186/s12939-019-0992-4

60. Kosiyaporn H, Julchoo S, Sinam P, Phaiyarom M, Kunpeuk W, Pudpong N, et al. Health literacy and its related determinants in migrant health workers and migrant health volunteers: a case study of Thailand, 2019. Int J Environ Res Public Health. (2020) 17:2105. doi: 10.3390/ijerph17062105

61. Adair LS, Fall CHD, Osmond C, Stein AD, Martorell R, Ramirez-Zea M, et al. Associations of linear growth and relative weight gain during early life with adult health and human capital in countries of low and middle income: findings from five birth cohort studies. Lancet. (2013) 382:52534. doi: 10.1016/S0140-6736(13)60103-8

62. Moore S, Kawachi I. Twenty years of social capital and health research: a glossary. J Epidemiol Community Health. (2017) 71:513-7. doi: 10.1136/jech-2016-208313

63. Murayama H, Fujiwara Y, Kawachi I. Social capital and health: a review of prospective multilevel studies. J Epidemiol. (2012) 22:17987. doi: 10.2188/jea.JE20110128

Conflict of Interest: The authors declare that the research was conducted in the absence of any commercial or financial relationships that could be construed as a potential conflict of interest.

Publisher's Note: All claims expressed in this article are solely those of the authors and do not necessarily represent those of their affiliated organizations, or those of the publisher, the editors and the reviewers. Any product that may be evaluated in this article, or claim that may be made by its manufacturer, is not guaranteed or endorsed by the publisher.

Copyright (c) 2022 Tian, Luo and Chen. This is an open-access article distributed under the terms of the Creative Commons Attribution License (CC BY). The use, distribution or reproduction in other forums is permitted, provided the original author(s) and the copyright owner(s) are credited and that the original publication in this journal is cited, in accordance with accepted academic practice. No use, distribution or reproduction is permitted which does not comply with these terms. 